\section{Cystoid macular} oedema in uveitis: an unsolved problem

Uveitis accounts for $10-15 \%$ of all cases of total blindness in the United States, ${ }^{1}$ and in Britain in 1996 there were an estimated 166140 people registered blind or partially sighted between the ages of 16 and 64 years, many of whom have uveitis as their reason for registration. One of the most important causes of both blindness and visual impairment is cystoid macular oedema (CMO), which is usually the sequela of longstanding intraocular inflammation. ${ }^{2}$

The incidence of $\mathrm{CMO}$ varies according to clinical syndromes. The highest incidences are reported as being between $28 \%$ and $52 \%$ in pars planitis, ${ }^{3-5} 24 \%$ in Behçet's syndrome ${ }^{6}$ and $30 \%$ in intermediate uveitis. ${ }^{7}$ Other uveitic disorders with which macular oedema has been associated include Harada's disease, idiopathic vasculitis and idiopathic panuveitis.

There is no effective form of treatment for uveitic $\mathrm{CMO}$, which is due, in part, to the limited understanding of the pathogenesis of $\mathrm{CMO}$ in patients with uveitis, but most importantly to the lack of randomised clinical trials comparing the efficacy of the available forms of therapy. Our current practice is mainly based upon case reports and uncontrolled series.

\section{Pathogenesis}

$\mathrm{CMO}$ may occur as a consequence of a number of mechanisms. ${ }^{8,9}$ Factors influencing the formation of retinal fluid, and $\mathrm{CMO}$ production, include the following: plasma and tissue oncotic pressures, capillary and tissue hydrostatic pressures, tissue compliance and blood-retinal barrier permeability. The blood-retinal barrier (both the inner and outer) can break down as a result of direct damage to the capillary endothelium, or as a result of loss of the autoregulatory control of blood flow, in which case the intraluminal capillary pressure rises,

Dr Gwenyth Freeman Moorfields Eye Hospital City Road London EC1V 2PD, UK Tel: $+44(0) 2075662016$ Fax: +44 (0)207566 2016

Received: 23 November 1999 Accepted in revised form: 15 August 2000 blood-brain (or blood-retinal) barriers, with a secondary accumulation of fluid in the extracellullar space. Starling ${ }^{11}$ was the first to suggest that fluid accumulation occurs when the rate of fluid production exceeds the rate of removal. As there is no lymphatic system in the retina, extracellular fluid must travel through the retina itself to reach either the vitreous or retinal circulation for removal.

Chronic intraocular inflammation leads to the disruption of the inner blood-retinal barrier located at the endothelium of the retinal vessels, with subsequent leakage of fluid. It is hypothesised that this is the mechanism by which anterior segment inflammation could lead to $\mathrm{CMO}$, via the release of inflammatory mediators, which could reach the posterior pole Free radicals, prostaglandins, serotonin, bradykinin, histamine, substance $\mathrm{P}$ and leukotrienes, as well as other mediators, are among the various possible factors responsible for the development of CMO. ${ }^{12,13}$ Perivascular sheathing by inflammatory cells can be seen in certain uveitides (sarcoidosis) and probably reflects the disruption of the retinal vascular endothelium.

Vitreous traction at the macula also has been proposed as a mechanism of CMO. ${ }^{14,15}$ Vitreous fibres connecting to the Müller cells in the macular area have been documented histologically. ${ }^{15}$ Swelling and degeneration of the Müller cells is reported to be present in early $\mathrm{CMO}$, indicating that dysfunction of Müller cells may lead to an accumulation of extracellular fluid in the retina. ${ }^{16}$ Supporting this concept, Hirokowa and associates ${ }^{17}$ have shown that uveitic eyes with complete vitreous detachments tend to have fewer macular changes and better visual acuities than those eyes without complete vitreous detachment.

Choroidal inflammation resulting in CMO may also occur due to disruption of the outer retinal barrier located at the level of the retinal pigment epithelium. This is thought to be the mechanism of CMO present in some conditions such as Vogt-Koyanagi-Harada disease and sympathetic ophthalmia.

There is also evidence that pigment epithelial function is diffusely involved in cases of both focal and generalised intraocular inflammation. ${ }^{19}$ 


\section{Clinical aspects}

The main complaint of patients with $\mathrm{CMO}$ is decreased or blurred vision. Clinically, classic CMO involves the presence of small intraretinal cysts around the fovea, arranged in a petaloid pattern that is often incomplete. A halo of retinal oedema with increased retinal thickness may surround the cysts. In mild cases, intraretinal cysts may not be visible clinically and only blunting of the foveal reflex may be present. If prolonged, the $\mathrm{CMO}$ will cause permanent structural damage.

\section{Histology}

Histologically, the cystoid spaces observed clinically in $\mathrm{CMO}$ are located in the outer plexiform layer and may extend into the inner nuclear layer. ${ }^{20,21}$ These cystoid spaces may coalesce to form large macular cysts, and full-thickness or lamellar holes may also develop. There may be concomitant hypertrophy and hyperplasia of the retinal pigment epithelium. Retinal glial cells may also migrate to the inner surface of the retina, ${ }^{20}$ causing epiretinal membrane formation.

\section{Diagnosis}

Fluorescein angiography is more sensitive in detecting CMO than is ophthalmoscopic examination, and has been used as a standard tool for diagnosis of CMO. In some cases, $\mathrm{CMO}$ can be demonstrated only on fluorescein angiography and is not suspected clinically. In a study by Schenck and Boke, ${ }^{22} 22 \%$ of patients with intermediate uveitis had oedema of the macula, the optic disc or both that was undetected by ophthalmoscopy. On fluorescein angiography, CMO can be demonstrated by diffuse leakage at the macular area with accumulation of fluorescein in the macular cysts. Leakage from the optic disc and perifoveal capillaries may also be present. Staining of the optic disc and leakage from the capillaries may also take place. ${ }^{13}$

Nussenblatt et al..$^{23}$ found that retinal thickness correlates better with visual acuity than the amount of fluorescein leakage, which correlates poorly. In this respect, measurement of retinal thickness, using techniques such as optical coherence tomography (OCT), can be very useful. Hee et al., ${ }^{24}$ in a survey study using $\mathrm{OCT}$, concluded that it appears useful for objectively monitoring retinal thickness. Theoretical resolution limits arehigh, and therefore it is a more sensitive method than slit-lamp biomicroscopy to detect small changes in retinal thickness. However, this method has limitations releated to the presence of opacification of the ocular media and difficulties exist with regard to standardisation of the reference position. Puliafito and colleagues ${ }^{25}$ correlated fundus examination and fluorescein angiography with OCT findings in 12 eyes and found that the latter was a helpful tool in evaluating patients clinically.
Another technique available is confocal scanning laser ophthalmoscopy (CSLO or SLO), which provides realtime images of the human fundus that can be evaluated at the time of the patient visit. Confocal laser scanning devices, with their minimal depth of focus, improve the ability to obtain good-quality images with reduced need for pupil dilation and clear media. Zambarakji et al. ${ }^{26}$ studied volumetric analysis of early macular oedema with SLO in diabetic retinopathy and concluded that this device is useful in quantification of macular oedema.

Functional testing, using both electrophysiological and psychophysical techniques, can also be done. A direct assessment of macular function can be achieved with pattern electroretinography (PERG), while psychological testing of macular function using colour contrast sensitivity can also provide complementary information regarding the functional state of the macula. Limited reports of the use of PERG in inflammatory eye diseases have appeared. ${ }^{27,28}$ It is likely that changes in the PERG may involve the latency of the P50 component, in addition to the more customary P50 amplitude reduction usually associated with macular dysfunction.

\section{Treatment}

Treatment of CMO in uveitis patients is not well established, and is certainly surrounded by controversy.

Topical anti-prostaglandins do not appear to be useful in treating uveitic CMD. ${ }^{2}$ Topical corticosteroids, however, can reduce the inflammation in the anterior segment of the eye and may be helpful in treating CMO caused by chronic iritis or iridocyclitis. ${ }^{2}$ On occasion, $\mathrm{CMO}$ secondary to intermediate uveitis may also respond to topical corticosteroids. ${ }^{2}$

Periocular steroids are the treatment of choice, especially in unilateral cases of CMO in which topical steroids are ineffective. ${ }^{2}$ The mechanism of penetration of corticosteroids into the eye, after periocular injection, is most likely to be trans-scleral. McCartney et al. ${ }^{29}$ used autoradiography to study the penetration of subconjunctivally injected hydrocortisone into both normal and inflamed rabbit eyes and found that penetration was much faster in the inflamed eyes. As a result of their study, they recommend that steroids should be injected immediately adjacent to the site of inflammation, rather than in a non-specific fashion. This study has been the basis for the placement of injections as close to the area of inflammation as possible. The injection can be given either as an orbital floor injection or as a posterior sub-Tenon's injection, which, in theory, is more likely to be effective due to the closer location of the drug to the macula. However, there is no clinical evidence published to support this assumption since no randomised clinical trials are available, which is mostly due to the large numbers needed to reach statistical significance when comparing the two techniques. Freeman et al. ${ }^{30}$ looked at the location of the repository steroid injection using both $\mathrm{A}$ and $\mathrm{B}$ ultrasound scanning immediately before and after the sub-Tenon's injection was given. They found that in $57 \%(8 / 14)$ of the 
injections given superotemporally, and in $30 \%(3 / 10)$ of the ones given inferotemporally, there had been successful delivery of the drug to the macular area. This paper stresses the difficulty of predicting the location of the medication without ultrasonography, as even experienced physicians were unable to improve on their performance with practice. Jennings et al..$^{31}$ found an increase in visual acuity in 6 of their 12 study eyes with CMO from various types of uveitis. They wondered whether the posterior sub-Tenon's injections were effective due to an improvement in blood-retinal barrier permeability, or whether other unspecified factors played a role. Yoshikowa et al. ${ }^{32}$ studied 29 patients with $\mathrm{CMO}$ secondary to uveitis in a prospective clinical trial using posterior sub-Tenon's injections of either methylprednisolone acetate or triamcinolone acetonide. They injected 39 eyes, and found after two to seven injections, with an interval of 2 weeks or more, that $56 \%$ showed an improvement in visual acuity of 2 Snellen lines or more. Most of the eyes which had relatively good visual acuity $(6 / 18$ or better) before the injections, showed better response than the others. The authors suggest that better results can be achieved when CMO is treated at an early stage. Helm et al..$^{33}$ reviewed controls of 18 consecutive idiopathic intermediate uveitis patients who received injections for CMO. Twelve of these 18 eyes improved by at least 2 lines of visual acuity, with the median time to improvement being 3 weeks.

Additionally, 2 patients improved with two injections, resulting in an improvement in visual acuity in 14 of 18 eyes. However, 4 of these eyes had a subsequent decline in vision at a median of 4 months after their injections. Visual improvement in this study was associated with a younger age and also possibly a history of no smoking.

Ocular complications associated with periocular corticosteroid injections include elevation of intraocular pressure and cataract formation. ${ }^{1}$ The contraindications for these procedures include steroid-induced glaucoma, hypersensitivity to any components of the injected substances, active necrotising scleritis and active ocular toxoplasmosis. ${ }^{2,34}$

Oral prednisolone may be a useful option in patients whose condition is bilateral or is unresponsive to periocular corticosteroids, ${ }^{2}$ and who do not have a formal contraindication to this type of therapy. Another unanswered question in the tissue of management of $\mathrm{CMO}$ is related to how effective systemic therapy can be when the patient failed to respond to a trial of posterior sub-Tenon's injections. The limited evidence discussed above regarding the correct position of the steroid injection would support the use of a trial of systemic therapy in those cases which failed to respond to periocular injection. Initial high doses, with slow taper, are usually needed to control the inflammatory process and to allow reduction of macular oedema. Too rapid a reduction can lead to recurrence. In certain cases unresponsive to oral corticosteroids alone, a combination of oral steroid and posterior sub-Tenon's injection of corticosteroids can be given for additive effect. ${ }^{2}$
Occasionally, intravenous steroid treatment can improve visual acuity when oral or periocular corticosteroids have failed to do so. ${ }^{35}$

There is controversy regarding the utilisation of acetazolamide in the treatment of uveitic CMO. Cox et al. ${ }^{36}$ in a prospective crossover randomised clinical trial involving 41 patients with a total of seven different conditions associated with $\mathrm{CMO}$, showed that acetazolamide could be useful as a first therapeutic option in uveitic cases, although in all their positive responders the effect stopped on discontinuation of the drug. This was reversible with reinstitution of therapy. There were at least 5 consecutive patients in each diagnostic group of whom only 6 in total had chronic uveitis from any cause. They found that all those who responded did so within 14 days. A taper was performed to assess the minimum dose required in each patient to maintain their best acuity, and most patients required $250 \mathrm{mg} /$ day. It is of note that the uveitic responders all had had CMO for 1 year or less, and no details were given about those who did not respond. Use of this drug is associated with few serious complications, even when it is taken for prolonged periods, and low doses usually produce a therapeutic effect. Farber et al. ${ }^{37}$ studied 37 patients in a two-period prospective randomised doublemasked crossover study which compared $500 \mathrm{mg}$ actazolamide twice a day for 1 month, with placebo. Unfortunately the study became more or less unmasked due to the intolerance of $19 \%(7 / 37)$ of the patients to the drug. Farber et al. reported a small but statistically significant improvement in visual acuity in those patients taking acetazolamide, but no improvement when the same patients were receiving placebo. There was no long-term follow-up on these patients to see whether the efficacy of the drug was maintained over time. ${ }^{37}$ Conversely, Guex-Crosier et al., ${ }^{38}$ in a prospective open study of 23 patients with CMO, 11 after cataract surgery and 12 with uveitis, concluded that acetazolamide and anti-inflammatory drops represent a good initial therapy for pseudophakic CMO, whereas posterior sub-Tenon's injections of steroid should be included in the initial therapy for all uveitis-induced $\mathrm{CMO} .{ }^{38}$ It is of note that these patients had a variety of aetiologies for their macular oedema and duration of CMO was very variable ( $269 \pm 235$ days). However, in those cases where the macular oedema resolved, it took $38 \pm 25$ days after injections were given and none relapsed in the follow-up, which was again variable at $7 \pm 5$ months. In a randomised masked crossover trial of acetazolamide for CMO analysing 37 patients with uveitis, Whitcup et al. ${ }^{39}$ found that a 4 week course of acetazolamide therapy resulted in a statistically significant, but small, decrease in CMO in patients with chronic uveitis. This, however, was not associated with an increase in visual acuity.

Immunosuppressive drugs are sometimes indicated in severe uveitis, and they are thought to produce a reduction in intraocular inflammation and consequently $\mathrm{CMO}^{2}$ These drugs are usually used in association with systemic steroids and mostly as steroid-sparing agents. Unfortunately, there do not appear to be any randomised 
double-masked prospective controlled clinical trials involving the use of any of these agents in treatment for CMO due to uveitis. Nussenblatt et al. ${ }^{40}$ studied 56 patients with sight-threatening intermediate or posterior uveitis in a randomised double-masked study comparing the efficacy of cyclosporine with prednisolone as treatment. Both groups did contain some patients with $\mathrm{CMO}$, but in these patients either treatment was successful in less than half. Other immunosuppressive drugs used in treatment for $\mathrm{CMO}$ in uveitis patients include azathioprine, methotrexate, tacrolimus (FK506) and mycophenolate mofetil (Cellcept). However, the papers discussing the use of these agents in treatment of uveitis do not address the specific issue of CMO even though visual acuity is used as an endpoint in most of the trials and it is likely that $\mathrm{CMO}$ was the main reason for poor vision. ${ }^{41-55}$

Hyperbaric oxygen has not been properly tested, but does not seem to be a practical therapeutic modality in the treatment of uveitic CMO. ${ }^{2}$

Grid laser photocoagulation has been proposed for the treatment of uveitic macular oedema. SuttorpSchulten et al. ${ }^{56}$ studied 6 eyes of 5 patients with longstanding CMO due to chronic uveitis who were treated with grid laser photocoagulation, and only 1 had an improvement in visual acuity. Larenoye et al..$^{57}$ studied 14 patients with CMO due to uveitis using a nonrandomised protocol and found visual improvement in half. They concluded that macular grid photocoagulation may be a valuable alternative therapy in these cases.

Vitrectomy may be beneficial in some cases of $\mathrm{CMO}{ }^{58}$ Vitrectomy may lessen or stabilise the amount of CMO in patients with uveitis whose condition is unresponsive to any other treatment, especially in chronic iridocyclitis, pars planitis and vitritis. Very few studies have evaluated vitrectomy as a therapeutic option for cases of uveitis, and these have almost without exception reported on cases in which the uveitis and CMO had been longstanding. Heiligenhaus et al. ${ }^{59}$ retrospectively reviewed their experience with vitrectomies in the preservation of vision in cases of chronic complicated uveitis. Overall, they found an $83 \%$ improvement in visual acuity $(23 / 28)$ eyes and vision was better than $6 / 24$ in 16 eyes. However, only 6 of these eyes had had CMO pre-operatively, with only 3 of these obtaining an improvement in visual acuity and this could take up to 15 months to occur. Verbraeken ${ }^{60}$ also reported a retrospective selection of 25 eyes with chronic uveitis undergoing vitrectomy. Fifteen of these eyes had $\mathrm{CMO}$ and 8 had improved vision afterwards. Kroll et al. ${ }^{61}$ found an improvement in CMO in 7 of 25 eyes in patients undergoing vitrectomy for uveitis secondary to juvenile rheumatoid arthritis. Dugel et al. ${ }^{62}$ studied vitrectomy as a therapy for 11 eyes in 19 patients having CMO and chronic uveitis refractory to all medical treatment. All eyes were found to have a spontaneous separation of the posterior vitreous face due to chronic inflammation. Seven eyes improved 4 or more lines in acuity, 2 remained unchanged and 2 worsened. The procedure was not without risk, and 7 eyes had multiple post- operative complications, including cataract formation, vitreous haemorrhage, tractional retinal detachment and rhegmatogenous retinal detachment with proliferative vitreoretinopathy. Other complications of importance, especially in younger patients, are CMO after surgery, and macular pucker. Important aspects such as the duration of $\mathrm{CMO}$ prior to the procedure and the response of the oedema itself to the procedure have not been properly addressed. Vitrectomy may have improved vision because of improvement in media clarity rather than specifically inducing changes to previous CMO. Also there seems to be no evidence that vitrectomy reduces the number of episodes of uveitis, even though some authors suggest this may occur. ${ }^{59}$

Vitrectomy may be a safer approach than immunosuppressive therapy when corticosteroids fail, but proper studies are needed to confirm this. Macular oedema in the presence of low-grade vitreal inflammation may itself be an indication for vitrectomy as there is some evidence that CD5+ B lymphocytes and TCR $\gamma \delta$ T cells are present in the vitreous in some cases of autoimmune uveoretinitis. ${ }^{63}$ These cells are implicated in perpetuating autoimmune inflammation, perhaps by continually presenting antigen, despite adequate immunosuppression. The Virectomy-Aphakic Cystoid Macular Oedema Study found a statistically significant improvement in visual acuity in patients undergoing vitrectomy surgery for chronic CMO after cataract extraction. ${ }^{18}$ The surgery needs to be done early, before there is a permanent alteration to the macula.

\section{Summary}

Most papers on the subject of CMO associated with uveitis are retrospective, combine patients with different disease aetiologies, at different stages of evolution, and often describe patients who were previous treatment failures with other therapies besides the one under consideration. There are almost no prospective randomised double-masked controlled studies. This is perhaps in part due to the relative sparsity of uveitis patients seen by many uveitis centres. At the moment, treatment is largely empirical, based in large part on the studies, and others, quoted above.

The need to regularly repeat courses of therapy, loss of efficacy of certain form of therapy after repeated use, and cumulative side-effects, all need to be taken into consideration when interpreting results and deciding upon the best approach to be adopted. The risks to the patient's well-being increase with the addition of systemic medication, and long-term steroid use can cause hypertension, induce or exacerbate diabetes, cause premature osteoporosis, cushingoid features, peptic ulceration and aseptic necrosis of the femoral head. Immunosuppressive drugs can be nephrotoxic, hepatotoxic, cause hypertension, gastric disturbances and excessive hair growth.

The assessment of macular changes, both structurally and functionally, is the key aspect in understanding visual loss in $\mathrm{CMO}$ and also in predicting potential visual 
recovery. The combined use of the various tools mentioned here, such as SLO, OCT and electrodiagnostic tests, may give us some of the necessary answers in this process. However, all these tests will need to be validated. A prospective analysis of $\mathrm{CMO}$ in cases of uveitis, especially if coupled with therapeutic intervention, will give us the opportunity to achieve this objective.

\section{References}

1. Nussenblatt RB. The natural history of uveitis. Int Ophthalmol 1990;14:303-8.

2. Tessler H, Lam S. Cystoid macular edema. In:. Pepose JS, Holland GN, Wilhelmus KR, editors. Ocular infection and immunity. St Louis: CV Mosby, 1996:553-89.

3. Henderly DE, Genstler AJ, Rao NA, Smith RE. Pars planitis. Trans Ophthalmol Soc UK 1986;105:227-32.

4. Henderly DE, Haymond RS, Rao NA, Smith RE. The significance of the pars plana exudate in pars planitis. Am J Ophthalmol 1987;103:669-71.

5. Smith RE, Godfrey WA, Kimura SJ. Chronic cyclitis. I. Course and visual prognosis. Trans Am Acad Ophthalmol Otolaryngol 1973;77:760-8.

6. Atmaca LS. Fundus changes associated with Behçet's disease. Graefes Arch Clin Exp Ophthalmol 1989;227:340-4.

7. Arocker-Mettinger E, Grabner G. Intermediate uveitis: clinical findings and treatment. Klin Monatsbl Augenheilkd 1989;194:249-51

8. Tso Mark OM. Animal modelling of cystoid macular oedema. Surv Ophthalmol 1984;28(Suppl):512-9.

9. Rocha G, Deschenes J. Pathology and treatment of cystoid macular oedema. Can J Ophthalmol 1996;31:282-8.

10. Klatzo I. Neuropathological aspects of brain oedema. J Neuropath Exp Neurol 1967;37:1-14.

11. Starling EH. On the observation of fluids from the consecutive tissue spaces. J Physiol (Lond) 1896;19:312.

12. Miyake K. Indomethacin in the treatment of postoperative cystoid macular oedema. Surv Ophthalmol 1984;28(Suppl):554-68.

13. Yannuzzi LA. A perspective on the treatment of aphakic cystoid macular oedema. Surv Ophthalmol 1984;28(Suppl):540-53.

14. Schepens CL, Avila MP, Jalkh AE, Trempe CL. Role of the vitreous in cystoid macular oedema. Surv Ophthalmol 1984;28(Suppl):499-504.

15. Sebag J, Balazs EA. Pathogenesis of cystoid macular oedema: and anatomic consideration of vitreoretinal adhesions. Surv Ophthalmol 1984;28(Suppl):493-8.

16. Tso MOM. Cystoid macular oedema. In: Tso MOM, editor. Retinal diseases: biomedical foundations and clinical management. Philadelphia: JB Lippincott, 1988:215-41.

17. Hirokawa $\mathrm{H}$, Takahashi M, Trempe CL. Vitreous changes in peripheral uveitis. Arch Ophthalmol 1985;103:1704-7.

18. Fung WE. Vitrectomy for chronic aphakic cystoid macular oedema: results of a national, collaborative, prospective randomised investigation. Ophthalmology 1985;92:1102-11.

19. Tso MOM. Pathology of cystoid macular edema. Ophthalmology 1982;89:902-15 or Trans Ophthalmol Soc UK 1980;100:408-13 or Ophthalmologica 1981;183:46-54.

20. Green WR. Retina. In: Spencer WH, editor. Ophthalmic pathology: an atlas and textbook. Vol 2. Philadelphia: WB Saunders, 1985:589-91.

21. Jampol LM. Macular oedema. In: Ryan SJ, editor. Retina. Vol 2. St Louis: CV Mosby, 1989:81-8.

22. Schenck F, Boke W. Angiographic findings in intermediate uveitis. Klin Monatsbl Augenheilkd 1988;193:261-5.
23. Nussenblatt RB, Kaufman SC, Palestine AG, et al. Macular thickening and visual acuity: measurement in patients with cystoid macular oedema. Ophthalmology 1987;94:1134-9.

24. Hee MR, Puliafito CA, Wong C, Duker JS, Reichel E, Rutledge B, et al. Quantitative assessment of macular oedema with optical coherence tomography. Arch Ophthalmol 1995;113:1019-29.

25. Puliafito CA, Hee MR, Lin CP, Reichel E, Schuman JS, Duker $\mathrm{JS}$, et al. Imaging of macular diseases with optical coherence tomography. Ophthalmology 1995;102:217-29.

26. Zambarakji HJ, Amoaku WM, Vernon SA. Volumetric analysis of early macular oedema with the Heidelberg retina tomograph in diabetic retinopathy. Ophthalmology 1998;105:1051-9.

27. Holder GE. Pattern electroretinography in patients with delayed pattern visual evoked potentials due to distal anterior visual pathway dysfunction. J Neurol Neurosurg Psychiatry 1989;52:1364-8.

28. Holder GE. The pattern electroretinogram in anterior visual pathway dysfunction and its relationship to the pattern visual evoked potential: a personal clinical review of 743 eyes. Eye 1997;11:924-34.

29. McCartney HJ, Drysdale IO, Gornall AG, Basu PK. An autoradiographic study of the penetration of subconjunctivally injected hydrocortisone into the normal and inflamed rabbit eye. Invest Ophthalmol Vis Sci 1965;4:297-302.

30. Freeman WR, Green RL, Smith RE. Echographic localisation of corticosteroids after periocular injection. Am J Ophthalmol 1987;103:281-8.

31. Jennings T, Rusin MM, Tessler HH, Cuhna-Vas JG. Posterior subtenon's injections of triamcinolone acetonide in uveitis patients with cystoid macular oedema. Jpn J Ophthalmol 1998;32:385-91.

32. Yoshikowa K, Kotake S, Ichiishi A, Sasamoto Y, Kosaka S, Matsuda H. Posterior subtenon injections of repository corticosteroids in uveitis patients with cystoid macular oedema. Jpn J Ophthalmol 1995;39:71-6.

33. Helm CJ, Holland GN. The effects of posterior subtenon's injection of triamcinolone acetonide in patients with intermediate uveitis. Am J Ophthalmol 1995;120:55-64

34. Min DI, Monaco AP. Complications associated with immunosuppressive therapy and their management. Pharmacotherapy 1991;5:s119-25.

35. Wakefield D, McCluskey P, Penny R. Intravenous pulse methylprednisolone therapy in severe inflammatory eye disease. Arch Ophthalmol 1986;104:847-51.

36. Cox SN, Hay E, Bird AC. Treatment of chronic macular oedema with acetazolamide. Arch Ophthalmol 1988;106:1190-5.

37. Farber MD, Lam S, Tessler HH, Jennings TJ, Cross A, Rusin $\mathrm{M}$. Reduction of macular oedema by acetazolamide in patients with chronic iridocyclitis: a randomised prospective crossover study. Br J Ophthalmol 1994;78:4-7.

38. Guez-Crosier Y, Othein-Girard P, Herbort CP. Traitement diférencié de l'oedème maculaire cystoide inflammatoire postopératoire et secondaire aux uvéites. Klin Monatsbl Augenheilkd 1992;200:367-73.

39. Whitcup SM, Czaky KG, Podgor MJ, Chew EY, Perry CH, Nussenblatt RB. A randomised masked crossover trial of acetazolamide for cystoid macular oedema in patients with uveitis. Ophthalmology 1996;103:1054-63.

40. Nussenblatt RB, Palestine AG, Chan CC, Stevens G, Mellow SD, Green SB. Randomised double-masked study of cyclosporine compared to prednisolone in the treatment of endogenous uveitis. Am J Ophthalmology 1991;112:138-46.

41. Nussenblatt RB, Palestine AG, Chan C-C. Cyclosporin A therapy in the treatment of intraocular inflammatory disease resistant to systemic corticosteroids and cytotoxic agents. Am J Ophthalmol 1983;96:275-82. 
42. De Smet MD, Rubin BI, Whitcup SM, Lopez JS, Austin HA, Nussenblatt RB. Combined use of cyclosporine and ketoconazole in the treatment of endogenous uveitis. Am J Ophthalmol 1992;113:687-90.

43. Holt FG, Krastel H, Breibart A, et al. Low dose methotrexate treatment in non-infectious uveitis resistant to corticosteroids. Ger J Ophthalmol 1992;1:142-4.

44. Yasiki H, Pazari H, Barnes CG, Tuzun Y, Ozygazan Y, Silman $\mathrm{A}$, et al. A controlled trial of azathioprine in Behçet's syndrome. N Engl J Med 1990;332:281-5.

45. Nussenblatt RB, Palestine AG, Chan CC. Cyclosporin therapy for uveitis: long term follow up. J Ocul Pharmacol 1985;1:369-81.

46. Vitale AT, Rodriguez A, Foster CS. Low dose cyclosporin A therapy in treating chronic, non-infectious uveitis. Ophthalmology 1996;103:365-74.

47. Nussenblatt RB, Palestine AG. Cyclosporine: immunology, pharmacology and therapeutic uses. Surv Ophthalmol 1986;31:159-69.

48. BenEzra D, Cohen E, Chajek T, Friedman G, Pizanti S, de Courten $\mathrm{C}$, et al. Evaluation of conventional therapy versus cyclosporine A in Behçet's syndrome. Transplant Proc 1988;20:136-43.

49. Atmaca LS, Batioglu F. The efficacy of cyclosporin A in the treatment of Behçet's disease. Ophthalmic Surg 1994;25:321-7.

50. Ozyazgan $Y$, Yurdakul S, Yaziki H, Tuzun B, Iscimen A, Tuzun $Y$, et al. Low dose cyclosporine A versus pulsed cyclophosphamide in Behçet's syndrome: a single masked trial. Br J Ophthalmol 1992;76:241-3.

51. Masuda K, Urayama A, Kogure M, Nakajima A, Nakae K, Inaba G. Double-masked trial of cyclosporin versus colchicine and long-term study of cyclosporin in Behçet's disease. Lancet 1989;I:1093-5.

52. Whitcup SM, Salvo EC, Nussenblatt RB. Combined cyclosporine and corticosteroid therapy for sight-threatening uveitis in Behçet's disease. Am J Ophthalmol 1994;118:39-45.
53. Mochizuki M, Masuda K, Sakane T, Ito K, Kogure M, Sugino $\mathrm{N}$, et al. A clinical trial of FK506 in refractory uveitis. Am J Ophthalmol 1993;115:763-9.

54. Sloper CM, Powell RJ, Dua HS. Tacrolimus (FK506) in the treatment of posterior uveitis refractory to cyclosporine. Ophthalmology 1999;106:723-8.

55. Larkin G, Lightman S. Mycophenolate mofetil: a useful immunosuppressive in inflammatory eye disease. Ophthalmology 1999;106:370-4.

56. Suttorp-Schulten MSA, Feron E, Postema F, Kijlstra A, Pothova A. Macular grid laser photocoagulation in uveitis patients. Br J Ophthalmol 1995;79:821-4

57. Larenoye CWTA, Van Schooneveld MJ, Treffers WF, Rothova A. Grid laser photocoagulation for macular oedema in uveitis or the Irvine-Gass syndrome. Br J Ophthalmol 1998;82:1013-6.

58. Limon SY, Bloch-Michel E, Furia M. One hundred vitrectomies in uveitis. In: Saari KM, editor. Uveitis update. Proceedings of the First International Symposium on Uveitis, Espoo, Finland. Amsterdam: Excerpta Medica, 1984.

59. Heiligenhaus A, Bornfeld N, Foerster MH, Wessing A. Longterm results of pars plana vitrectomy in the management of complicated uveitis. Br J Ophthalmol 1994;78:549-54.

60. Verbraeken $H$. Therapeutic pars plana vitrectomy for chronic uveitis: a retrospective study of the long-term results. Graefes Arch Clin Exp Ophthalmol 1996;234:288-93.

61. Kroll P, Romstock F, Grenzebach UH, Wiegand W. Fruhvitrektomie bei endogener juvinier uveitis intermedia: eine Langzeitstudie. Klin Monatsbl Augenheilkd 1995;206:246-9.

62. Dugel PU, Rao NA, Ozlwe S, Liggett PE, Smith RE. Pars plana vitrectomy for intraocular inflammation-related cystoid macular edema unresponsive to corticosteroids. Ophthalmology 1992;99:1535-41.

63. Liversidge J, Dick A, Cheng YF, Scott GB, Forrester JV. Retinal antigen specific lymphocytes, TCR $\gamma \delta$ cells and CD5+ $B$ cells cultured from vitreous in acute sympathetic ophthalmitis. Auto-immunity 1993;15:1-10. 